\title{
REPRESENTAÇÃO DO DOWN E CONFLITOS COM O DIFERENTE: ASPECTOS DISCURSIVOS DO PROJETO "CLARINHA", UMA BONECA COM TRAÇOS DA SÍNDROME DE DOWN*
}

Cláudio Márcio do Carmo**

\begin{abstract}
Resumo: O presente artigo se apresenta como parte de um projeto maior, intitulado "Inserção, representação e construção identitária de minorias e grupos vulneráveis na mídia", que utiliza o quadro teórico-metodológico da Análise Crítica do Discurso de Norman Fairclough. O interesse recai sobre o modo como esses grupos são silenciados, mesmo quando, aparentemente, são inseridos na mídia, e sobre os conflitos e embates discursivos advindos dessa tentativa de inclusão. Neste trabalho, são analisados dois textos, um publicado na revista "Época", antes do lançamento de Clarinha, boneca com traços da Síndrome de Down, e outro publicado na "Folha de São Paulo", após seu lançamento. A análise indica o hibridismo discursivo, apontando diferentes visões sobre o grupo que a boneca representa, havendo uma tensão entre o lado social e o objetivo publicitário. Permeando esse viés, percebe-se um despreparo geral para lidar com a diversidade.

Palavras-chave: mídia; representação; Síndrome de Down; discurso.
\end{abstract}

\footnotetext{
* Este texto é uma versão ampliada do trabalho apresentado em comunicação oral no VIII Encontro Nacional de Interação em Linguagem Verbal e Não-Verbal (VIII ENIL) e no II Simpósio Internacional de Análise Crítica do Discurso (II SIACD), eventos concomitantes ocorridos na Universidade de São Paulo (USP), no período de 8 a 10 de agosto de 2007.

** Professor Adjunto de Lingüística e Língua Portuguesa da Universidade Federal de São João delRei. Doutor em Lingüística Aplicada. E-mail: <claudius@ufsj.edu.br>.
} 


\section{INTRODUÇÃO}

Inserido dentro do quadro teórico-metodológico da Análise Crítica do Discurso (doravante ACD), tal qual concebido por Fairclough (1989, 1995, 2001a, 2001b), este trabalho faz parte de um projeto maior intitulado "Inserção, representação e construção identitária de minorias e grupos vulneráveis na mídia”, desenvolvido no âmbito do Programa de Mestrado em Letras: Teoria Literária e Crítica da Cultura, da Universidade Federal de São João del-Rei (PROMEL-UFSJ), agregando também pesquisas de Iniciação Científica. Dentro desse projeto, nosso interesse recai sobre as formas de representação e construção identitária desses grupos e sobre o silenciamento deles, mesmo quando, aparentemente, são inseridos num espaço importante de difusão do pensamento e da informação como a mídia.

Pretende-se refletir sobre a imbricação discursiva evocada na constituição das identidades de variados grupos que podem ser colocados debaixo dessa denominação, aqui, especificamente o dos portadores da Síndrome de Down. Parte-se do princípio de que, a partir das pistas lingüísticas encontradas na materialidade do texto, algumas questões sociais e culturais podem ser trazidas à tona numa tentativa de refletir sobre alguns pontos de vista a respeito desse grupo.

Nosso corpus são dois textos da mídia impressa, quais sejam, "Uma boneca com Down", publicado na revista "Época" de 5 de março de 2007, antes do lançamento de Clarinha, boneca com traços da Síndrome de Down, inspirada na personagem Clarinha, que foi interpretada por Joana Mocarzel, na novela "Páginas da Vida", da Rede Globo (Texto A), e "Boneca de 'Páginas da vida' sofre rejeição", publicado na "Folha de São Paulo" (Texto B), em 15 de março de 2007, após seu lançamento.

A análise indica que o hibridismo discursivo aponta para diferentes visões sobre o grupo que a boneca representa, havendo uma tensão entre o lado social, cujo objetivo é o de trazer a diversidade à baila, refletindo sobre a necessidade de inclusão e visibilidade social do grupo, e o lado publicitário, que visa ao lucro, mas pode ter seu pleito "prejudicado", se o produto não tiver "saída" no mercado por representar um grupo que não seja o considerado "normal". Nesse 
sentido, permeando esse viés, ainda é possível perceber o despreparo geral para lidar com a diversidade na forma de preconceito e rejeição.

Nessa reflexão, dividimos o texto em quatro seções: uma dedicada a esclarecer questões relativas ao projeto Clarinha e à situação do portador da síndrome de Down; uma sobre mídia, discurso e representação; outra sobre a análise crítica do discurso e seus pressupostos teórico-metodológicos; e ainda outra em que buscamos, na materialidade lingüística dos textos, os elementos lingüístico-discursivos para uma análise da situação que envolve o projeto Clarinha em relação à sociedade e à cultura atuais com base nos textos do corpus. Seguem-se algumas considerações, as referências bibliográficas e os textos para análise que foram reproduzidos ao final.

\section{CARACTERIZAÇÃO DO "PROJETO CLARINHA", A SITUAÇÃO E A REPRESENTAÇÃO DO PORTADOR DA SÍNDROME DE DOWN}

O chamado "projeto Clarinha" originou-se da vontade de duas mães de portadores da Síndrome - a estilista Andréia Barbi e a dentista Audrey Bósio - de introduzir no mercado uma boneca que contemplasse o grupo de portadores de Down. O projeto, desde 2005, estava com dificuldades para ser implantado, já que era necessário encontrar uma fábrica que produzisse as bonecas em escala industrial (cf. MACHADO, 2007).

Tal projeto é extremamente importante numa conjuntura em que os direitos humanos têm sido colocados em discussão e as chamadas minorias e os grupos vulneráveis têm, em alguns momentos e casos, ganhado voz e visibilidade.

Neste trabalho, procuramos problematizar as concepções de minorias e de grupos vulneráveis começando com Séguin (2002, p. 12), para quem "as primeiras seriam caracterizadas por ocupar uma posição de não-dominância no país onde vivem" e, no segundo caso, os grupos poderiam se "constituir num grande contingente numericamente falando [...]". Embora com nomenclatura diferenciada, a autora esclarece que tanto os grupos vulneráveis quanto as minorias sofrem discriminação e 
são vítimas da intolerância, uma das razões que a leva a não se preocupar em trabalhar essas categorias de forma muito distinta.

Trabalhando essa questão, Adorno (1995, p. 321) explica que grupos considerados dominantes "utilizam da violência como se fossem meios naturais de solução de conflitos, seja nas relações entre classes sociais, seja nas relações intersubjetivas". Nesse sentido, a violência torna-se um dos maiores fatores geradores da vulnerabilidade, o que pode não ter a ver especificamente com a idéia de quantidade indicada pela palavra 'minoria'.

É relevante buscar também subsídios em Zaluar (1997, 1999, 2000, 2001), cujos trabalhos relacionam essa temática à formação de gangues, galeras e quadrilhas e a um problema educacional. Como podemos perceber, todos os autores indicam que minorias e grupos vulneráveis originam-se em relações de assimetria social (econômica, educacional, cultural etc.). Nesse sentido, minoria pode ser definida a partir de uma particularização de um grupo, já que a maioria se define por um agrupamento generalizado, ou seja, por um processo de generalização baseado na indeterminação de traços, os quais indicam um padrão de suposta normalidade, considerada majoritária em relação ao outro que destoar dele. A vulnerabilidade advém, pois, de pressões desse suposto padrão de normalidade que pressiona tudo e todos que possam ser considerados diferentes. A violência, por sua vez, tanto pode ser física quanto originária dessa pressão, que muitas vezes, na forma de preconceito e rejeição, marginaliza e discrimina o diferente.

É dentro dessa perspectiva que tratamos o grupo de portadores da síndrome de Down, cujos indivíduos nascem com um cromossomo extra no par 21. Isso faz com que o número comum de 46 cromossomos passe para 47, acarretando uma condição genética que limita o crescimento e o desenvolvimento do indivíduo. Por isso, essa condição também é chamada de "Trissomia do cromossomo 21" ou "Trissomia $21 "$.

De acordo com O’Regan (2007, p. 43), não há uma razão específica para a ocorrência da síndrome, uma vez que esse cromossomo extra tanto pode vir do espermatozóide do pai quanto dos óvulos da mãe, afetando qualquer um, independentemente de raça ou origem. $\mathrm{O}$ autor explica que a primeira descrição dessa síndrome aconteceu em 
1866, feita pelo Dr. John Langdon Down, que foi homenageado com o empréstimo de seu sobrenome à síndrome.

Ainda segundo O'Regan, essa condição pode acometer o bebê logo após a concepção, sendo que mulheres que concebem após os 35 anos são mais susceptíveis a terem bebês com Down, embora a idade do pai, a priori, não leve à mesma condição. Por outro lado, casais que possuam um filho com Down têm mais chances de ter outro filho portador. Em termos percentuais, nasce um bebê com Down a cada mil nascimentos.

Em adição, torna-se importante frisar a importância de individualizá-los, já que, embora tenham crescimento e desenvolvimento afetados, nem todos apresentam todos os sintomas. O'Regan (2007, p. 44) destaca as seguintes características físicas e condições do portador da Síndrome de Down:

a) baixo peso e pouco comprimento ao nascer;

b) olhos puxados;

c) rosto com aparência reta abaixo do nariz;

d) nuca reta;

e) cabelo baixo e um pouco desigual na nuca;

f) boca pequena, mas língua grande, o que a torna um pouco saliente - um treinamento pode minimizar este aspecto;

g) tônus muscular reduzido, que melhora com a idade;

h) altura inferior à média [...]

i) problemas cardíacos;

j) problemas auditivos;

1) doença da tireóide quando em idade avançada;

m) problemas com o peso;

n) pele seca;

o) tosse e resfriado.

A despeito dessa gama de problemas, o autor chama atenção para o fato de eles serem extremamente capazes. Ou seja, infere-se daí que o 


\section{4}

portador da síndrome de Down possui limitações e não incapacidade. Para além dessas características, é importante então que sejam notados e respeitados e que possam melhorar sua auto-estima. Esse é, por exemplo, o anseio de Werneck (1992) no trabalho "Muito prazer, eu existo: um livro sobre o portador da síndrome de Down". E, nesse sentido, o projeto Clarinha parece vir ao encontro dessa necessidade, ou seja, da necessidade de tornar visível uma parcela da população que tem pouca ou nenhuma visibilidade, uma vez que, mais que por suas capacidades, é "vista" e identificada pelo viés de suas limitações. Conforme nossa proposta, é importante que repensemos e problematizemos a forma como esse grupo tem sido re(a)presentado, para que inclusive a auto-imagem que fazem de si possa promover uma melhor forma de vida, a partir de suas capacidades, que precisam ser estimuladas (ver, por exemplo, para discussões relevantes a esse respeito, o estudo de COSTA, 1996 e o de PVESCHEL, 1993).

Percebendo o texto como um produto sócio-historicamente situado e representativo de uma realidade, pretende-se empreender uma reflexão crítica sobre a construção discursiva dessa boneca enquanto projeto de representação do grupo e, por isso, objeto discursivo em dois importantes momentos: o anterior e o posterior à sua criação, aqui representados por dois textos, um de cada momento. Para tanto, é importante elucidar a agenda da $\mathrm{ACD}$, que vê qualquer porção da linguagem como passível de carregar valores e promover, a partir da análise, reflexões sociais, culturais e ideológicas. Dessa forma, nas próximas seções, tentaremos esclarecer alguns pontos relevantes da relação entre mídia, discurso e representação e, depois, da agenda da ACD, de forma a constituir um aparato teórico-metodológico para as observações e reflexões que empreenderemos.

\section{MÍDIA, DISCURSO E REPRESENTAÇÃO}

Ao analisarmos a produção midiática, ficamos diante do estatuto contraditório de sua natureza muitas vezes considerada factual, quando tomamos, por exemplo, os textos jornalísticos. Entretanto, assumindo por base o ponto de vista a partir do qual todo texto é uma 
representação da realidade, começamos nossa discussão sobre representação a partir da análise da visão de Moscovici e Nemeth (1974), para quem:

As representações sociais são conjuntos dinâmicos, seu status é o de uma produção de comportamentos e relações com o meio, o de uma ação que modifica uns e outros, e não o de uma reprodução [...], nem o de uma reação a um estímulo exterior determinado. [...] são sistemas que têm uma lógica própria e uma linguagem particular, uma estrutura de implicações que se referem tanto a valores como a conceitos [juntamente com] um estilo de discurso próprio. Não as consideramos como opiniões sobre, nem imagens de, mas como "teorias", como "ciências coletivas" suigeneris, destinadas à interpretação e à construção da realidade. (p. 48)

Esse conceito pode ser considerado um indicador do que seria colocado como parâmetro para o entendimento desse termo na ACD, já que, ao tomar de Gramsci sua noção de hegemonia, a coloca como um "equilíbrio instável” (cf. FAIRCLOUGH, 2001a, 2001b), ou seja, as representações - assim como o status quo de uma situação - sempre poderão ser desafiadas a partir de tensões discursivas que causem instabilidade e, quiçá, mudanças. A perspectiva de Moscovici e Nemeth (1974) parte de uma visão da Psicologia Social, mas também calcada nos postulados da Sociologia (cf. FARR, 2003).

Mazzotti (2002), por exemplo, explica que, ao formar a representação de um objeto, o sujeito (individual ou coletivo), de certa forma, o constitui, o reconstrói em seu sistema cognitivo, de modo a adequá-lo ao seu sistema de valores. Esse sistema de valores, por sua vez, depende de sua sócio-história e do contexto social e ideológico no qual está inserido. Isso corrobora a visão da ACD de que é possível confrontar o que está "pronto", de maneira a possibilitar o desafio de uma realidade tida como verdadeira, natural e consensual.

Nesse sentido, a ACD tem sido um importante referencial no estudo da linguagem em relação à sociedade e vários trabalhos 


\section{6}

têm sido desenvolvidos a respeito de discursos sobre grupos inseridos na mídia, tais como Caldas-Coulthard $(1993,1996)$ e Heberle (1997, 2000) sobre gênero social ("gender"); Magalhães (2004), Carmo (2005) e Caetano (2007), a respeito do negro e de relações raciais, dentre outros.

Retornando às questões relativas à mídia, pode-se afirmar que a comunicação de massa é, sobretudo, um campo de articulação da linguagem e a massificação é que a relaciona com o campo específico da mídia. Para Rodrigues (s.d.), o campo da mídia é um campo de articulação da sociedade que é autônomo em termos das práticas sociais, sendo construtor de um discurso fechado sobre si, capaz de produzir modelos imaginários, que lhe trazem legitimidade. Por isso, Rodrigues (1988, p. 143) define os "campos sociais" como "esferas de legitimidade". O que pode ser questionado é essa autonomia, uma vez que todos os campos são chamados de forma imbricada na esfera social, na construção dos sentidos sociais.

Para Rodrigues (1988), os campos sociais são capazes de ditar regras discursivas e as maneiras de dizer algo, numa tentativa de impor uma ordem axiológica, projetando-a na maior quantidade de campos possível. Por isso, os processos de comunicação se relacionam de forma estreita à esfera pública, onde tudo o que for proclamado ganhará notoriedade, isto é, visibilidade social. Esse pensamento mostra a comunicação tanto como instrumento para os indivíduos obterem conhecimento como um processo que institui um espaço público. Deve-se ressaltar que, como todos os campos possuem, via de regra, um espaço, a composição do campo midiático não está isenta de conflitos, ou seja, sempre haverá formas de desafiar uma ordem axiológica.

Parece ser disso que Fairclough (1995) fala quando afirma que, na ordem do discurso midiático, existe sempre uma tensão entre os discursos públicos e privados que a delineiam, devido ao papel que a mídia precisa cumprir de mediadora dessa arena. Entretanto, há sempre 
uma relação dialógica, nunca unilateral, pois, ao sofrer pressões advindas dessa tensão, ela também as influencia.

Jovchelovitch (2003), por exemplo, calcada em Habermas, argumenta que a esfera pública é o lugar da alteridade que fornece às representações sociais o local onde podem ser cultivadas e estabelecidas, uma vez que, segundo ela, há uma ligação entre alteridade, construção simbólica, espaço público e as representações sociais. E, nesse sentido, é importante frisar a possibilidade de contrapor essas representações, de reconstruir ou estabelecer novas ligações nesse espaço.

Estudos em comunicação possuem e requerem para si um espaço teórico e metodológico próprio. Entretanto, a utilização de teorias discursivas tem orientado trabalhos produzidos na área (cf. PINTO, 1999; FAUSTO NETO, 1999) e vários lingüistas têm se interessado pelo estudo discursivo de diferentes modalidades midiáticas (cf. FOWLER, 1991; FAIRCLOUGH, 1995; GARRET; BELL, 1998; SCOLLON, 1998).

Garret e Bell (1998) organizam uma obra - Approches to media discourse - trazendo os mais relevantes trabalhos produzidos na interface discurso e comunicação, intentando contribuir tanto para iniciantes na área, disponibilizando diferentes abordagens para pesquisa, quanto para pesquisadores, trazendo o "estado da arte" nos estudos do discurso midiático.

Para Garret e Bell (1998, p. 3), o estudo do discurso midiático é importante porque (a) a mídia é uma fonte rica e acessível de dados para pesquisa e ensino; (b) o estilo dela influencia e representa o uso e as atitudes lingüísticas de uma comunidade; e (c) o uso da mídia pode revelar muito sobre o significado social e os estereótipos projetados através da linguagem e da comunicação. Por isso, ao estudar o que é veiculado e noticiado pela mídia, Fowler (1991, p. 4) explica que

notícia é uma representação do mundo na linguagem, porque linguagem é um código semiótico, ela impõe uma estrutura de valores, de origem social e econômica, sobre tudo que é representado; e, portanto, inevitavelmente a notícia, como todos 
os discursos, construtivamente padroniza aquilo de que fala. Notícia é uma representação nesse sentido de construção. Não é uma reflexão valorativamente livre sobre os fatos.

Haverá, nesse sentido, no universo da notícia, sempre um paradoxo ideológico entre o conflito/dissenso e o consenso, que se relaciona a questões de autoridade e poder, que são construídas discursivamente e representadas na e pela linguagem.

\section{ANÁLISE CRÍTICA DO DISCURSO: PRESSUPOSTOS TEÓRICO-METODOLÓGICOS PARA A INVESTIGAÇÃO DA RELAÇÃO LINGUAGEM, SOCIEDADE E CULTURA}

Conforme Fairclough (1995, 2001a, 2001b), um dos maiores objetivos da Análise Crítica do Discurso é buscar um método interdisciplinar sistemático que forneça elementos aos analistas para buscarem e explorarem relações opacas de poder que ocorrem nas práticas discursivas, nos eventos discursivos e nos textos, de forma que sejam encontradas as estruturas sociais, culturais e institucionais de que partem, dentro de uma visão da linguagem como prática social.

Nesse sentido, em Media Discourse, Fairclough (1995) procura explicitar a relação dialética entre o discurso e a estrutura social, já que cada evento discursivo deverá ser analisado enquanto texto, prática discursiva e prática social, de forma que seja possível refletir a respeito da produção, da distribuição e do consumo dos textos. Para o autor, o discurso se materializa nos textos que são ao mesmo tempo exemplos de prática discursiva, por serem um local em que diferentes discursos estão em constante conflito, produzindo embates e estabilidades, e prática social, pois fazem parte de um momento específico de uma cultura se significando e re-significando na sociedade da qual fazem parte. 
A análise da prática discursiva estaria também ligada a três tendências de mudança discursiva a que o autor chama de democratização, comodificação e tecnologização. Para Fairclough, as mudanças socioculturais se projetam no discurso na forma de tensão, conflito, estabilidade e rearticulação. Trabalhando-se essas tendências, a análise da primeira forneceria as bases para a problematização das desigualdades sociais, sejam elas ligadas a classe, gênero social, etnia etc.; a segunda se ligaria a uma crescente visão das relações sociais baseadas na produção e consumo de bens; e a última, ao entendimento das tecnologias discursivas como técnicas de transferência contextuais e estratégias discursivas, como o uso de entrevistas, aconselhamento e propagandas para concepção de um determinado evento discursivo.

Fairclough (1995) vê a mídia, portanto, como representação, por isso ele chama a atenção para o fato de em qualquer representação se ter que decidir sobre o que incluir ou excluir e sobre o que estará em primeiro ou segundo plano, pois nesse momento representações, identidades e relações estão sendo construídas e engendradas discursiva e ideologicamente nas proposições do texto.

Por isso, para o autor (p. 16-17), "a análise do discurso pode ser entendida como uma tentativa de mostrar as ligações sistemáticas entre textos, práticas discursivas e práticas socioculturais". Essa proposta calca-se na teoria sistêmica da linguagem para ver o texto sob uma perspectiva multifuncional, isto é, de acordo com as três metafunções de Halliday (1985a): ideacional, ligada ao universo de idéias e conceitos veiculados; interpessoal, ligada ao aspecto interativo da linguagem e as relações sociais e de poder manifestas nos textos; e textual, ligada ao próprio sistema lingüístico.

Para Fairclough, ver os textos dessa maneira facilita a ligação entre análise da linguagem e análise social, pois questões de 
conhecimentos, valores, crenças e ideologia estariam dentro do processo de representação, ligando-se à função ideacional; questões de relações e identidades sociais, bem como poder, estariam ligadas à função interpessoal; e as questões internas ao sistema lingüístico estariam ligadas à função textual. A metafunção ideacional estará manifesta no texto através, principalmente, da transitividade, que é mostrada pelos tipos de processos a que os verbos utilizados levam, bem como aos participantes evocados e às circunstâncias. A metafunção interpessoal estará manifesta pela modalização, responsável pela expressão dos julgamentos e atitudes das pessoas envolvidas. E a textual estará ligada à própria organização da mensagem no texto, principalmente através da seqüência tema (primeiro elemento de uma frase até o elemento que tiver função na transitividade) e rema (que se inicia no primeiro elemento com função na transitividade e vai até o final da frase).

Dentro da perspectiva sistêmico-funcional, "o texto pode ser estudado como processo ou como produto e, em ambos os casos, interpretar um texto significa mostrar como ele deriva do sistema e, portanto, por que ele significa o que ele significa" (HALLIDAY, 1985b, p. 30). Assim a linguagem, conforme explanam Matthiessen e Halliday (1997), é tomada como uma ordem do sistema que pode ser investigada (1) acusticamente, (2) neuro-fisiologicamente, (3) culturalmente e (4) lexicogramaticalmente - em termos de estratos semânticos. E conceber a língua dessa forma requer, sobretudo, pensá-la como um sistema de escolhas e como um recurso comunicacional e construtor da realidade.

Conforme observa Eggins (1994, p. 1-2), a abordagem sistêmica está sendo reconhecida como uma teoria que provê uma estrutura teórica para interpretação e descrição muito útil ao ver a linguagem como um recurso estratégico de produção de sentido. Essa é a razão da preocupação com o como as pessoas usam a linguagem e com o como ela é estruturada para o uso.

Uma análise sistêmico-funcionalista levaria a entender como a linguagem é usada, pois "ela não é arbitrária", já que deriva da necessidade de satisfazer as próprias necessidades humanas, tendo funções específicas em cada contexto (cf. HALLIDAY, 1985a; 
MATTIESSEN; HALLIDAY, 1997; HALLIDAY; MATTIESSEN, 2004). Por isso, toda linguagem poderia ser explicada com base no que Halliday chama de tipos de significado: o ideacional (experiencial e lógico); o interpessoal e o textual, já pontuados anteriormente.

A análise de uma oração passaria sempre por esses três significados ou metafunções, uma vez que a gramática contida nela indicaria: (a) como o falante concebe a realidade à sua volta e como a gramática pode ser usada para passar suas experiências, percebendo o significado como construtor da realidade e como configurações do mundo - pessoas, qualidades, circunstâncias, dentre outras; (b) como o falante interage com outras pessoas, revelando a natureza das relações sociais interpessoais, travadas entre aqueles que estão fazendo uso da linguagem; e (c) como o falante organiza a comunicação e as estruturas que geram essa comunicação.

É nesse ínterim que se pode perceber por que a gramática de Halliday é sócio-semiótica, ou seja, porque trata a linguagem e o contexto social como sendo níveis que se complementam na produção do sentido na comunicação de significados.

Para Halliday (1985a), a interpretação do contexto social inclui a análise de dois contextos: um contexto de situação (imediato) e um contexto de cultura (concebido pelo grupo). E trabalha o contexto de situação, utilizando-se de três variáveis: campo (field), relações (tenor) e modo (mode): o primeiro se ocupa da natureza da ação social, buscando os participantes engajados na situação comunicativa e em como eles representam suas experiências; o segundo refere-se a quem participa da conversa em termos de marcação de status e relações sociais interpessoais; e o último é referente ao que os participantes esperam da linguagem e de que forma organizam seu texto.

Em outras palavras, o contexto situacional, segundo o autor, sinteticamente compõe-se de três categorias, que seriam o campo, o tópico da situação, as relações, os papéis sociais desempenhados na interação, e o modo, o papel da linguagem dentro da interação. Estas categorias, por sua vez, correspondem aos componentes ideacional, interpessoal e textual.

Todas as metafunções estariam operando sempre conjuntamente para construção da visão de mundo daquele que se serve do sistema lingǘstico. E dentro desse sistema haveria sempre inter-relação. A 
metafunção ideacional estaria associada ao campo, realizando-se através da transitividade; a metafunção interpessoal estaria associada às relações, realizando-se através da modalidade e, por fim, a metafunção textual estaria associada ao modo, realizando-se através de estruturas temáticas, de informação e dos mecanismos de coesão.

Por essa razão, conforme especifica Martin (2001), a oração em cada metafunção é vista de uma maneira diferente: (a) na metafunção ideacional, a oração é vista como representação; (b) na metafunção interpessoal, como interação; e (c) na metafunção textual, como mensagem.

Como a metafunção ideacional engendra recursos para construirmos nossa experiência do mundo ao nosso redor e dentro de nós (MATTHIESSEN; HALLIDAY, 1997), durante a análise da transitividade, seria necessário se ater aos processos a que os verbos utilizados levam e aos participantes desses processos. De acordo com Heberle (2000, p. 299), trata-se de analisar quem faz o quê a quem e em quais circunstâncias. Como faremos referência a esse sistema por várias vezes na análise, faremos dele um pequeno resumo.

Em termos de processos, Halliday (1985a, p. 102-137) reconhece três tipos principais: (1) material, ligado ao processo do fazer (ex.: agir, comprar, andar, dentre outros), significando que um sujeito explicitamente pratica a ação expressa pelo verbo; (2) mental, ligado a verbos de sentimento, pensamento e percepção (ex.: acreditar, sentir, amar, dentre outros); (3) relacional, representado pelos verbos de ligação, os verbos do ser ("being"), que estabelecem atributos e relações de posse (ex.: parecer, ser, estar, dentre outros). E três subtipos, quais sejam: (a) comportamental, referente ao comportamento fisiológico e psicológico do indivíduo; (b) verbal, referente ao ato de dizer; (c) existencial, representado pelos verbos que indicam existência propriamente dita ("there to be" = haver) ou acontecimento.

Cada processo, por sua vez, evocaria um tipo de participante, ou seja, o processo material evocaria como participante um ator e/ou uma meta/alcance/beneficiário; o mental, um experienciador e um fenômeno; o relacional, embora não obrigatoriamente, uma característica, um valor, um portador, um identificado ou um identificador; o comportamental, um comportante e/ou um alcance; o 
verbal, um dizente e uma verbiagem - às vezes, um receptor ou um alvo; e o existencial evocaria um existente (cf. HALLIDAY, 1985a; HALLIDAY; MATTHIESSEN, 2004). Em todos os tipos de frases, independentemente do processo, podem ocorrer livremente circunstâncias.

Essa explanação nos leva a compreender tanto por que Locke (2004, p. 2) sintetiza a ACD afirmando que ela deve ser descrita como uma orientação com o potencial de transformar o modus operandi de um conjunto de métodos de pesquisa, quanto às pretensões de Fairclough (2005) de mostrá-la numa perspectiva mais transdisciplinar que interdisciplinar.

Em busca de uma orientação analítica capaz de fornecer elementos para trabalhar as diferentes questões ligadas à relação entre linguagem, sociedade e cultura, são necessárias contribuições de várias áreas e, muitas vezes, a derrubada das fronteiras entre elas.

Wodak (2004) explana que o campo disciplinar da ACD tem sido utilizado por pesquisadores interessados no estudo dos discursos institucional, político, de gênero social e da mídia por materializarem relações mais ou menos explícitas de luta e conflito. Por isso, pode-se afirmar que o espaço ideal para o uso de uma abordagem lingüística crítica são os discursos que envolvem questões de desigualdade que servem de âncora e sustentáculo aos conflitos advindos de relações sociais conflituosas. Como a autora ainda esclarece, a ACD possui como agenda a investigação crítica de como a desigualdade social é expressa, sinalizada, constituída, legitimada através do uso da linguagem e do discurso.

E essa é a visão que adotamos neste trabalho frente a uma tentativa de representação e inclusão do portador de necessidade especial - o Down - e os conflitos sociais dela advindos na forma de embate entre teoria e prática, entre o pensamento e o fato social, entre as condições reais e efetivas de inclusão e outras questões ligadas à desigualdade e ao preconceito com que são vistos, representados e identificados os membros pertencentes ao grupo.

O quadro, tal qual idealizado, pode dar indicações, a partir de categorias lingǘstico-discursivas utilizadas na produção dos discursos materializados nos textos a criação e/ou (re)produção de uma identidade 
social para esse grupo, principalmente quanto ao questionamento da produtividade da presença do grupo na sociedade, se se pensar na pouca (ou nenhuma) visibilidade que possuem e na possível rejeição social à boneca, conforme Castro (2007), que traz as características do grupo.

Tomando a visão tridimensional da ACD, nossa análise contemplará:

a) a prática textual, pois serão buscados alguns mecanismos lingǘstico-discursivos de construção textual, em especial aqueles que se mostrarem produtivos na construção, (re)produção de uma identidade social do portador da síndrome de Down;

b) a prática discursiva, já que serão buscados os elementos capazes de ajudar na reflexão sobre o processo de produção, distribuição e consumo dos textos que veiculam as idéias acerca do projeto Clarinha e, por conseguinte, da inclusão/exclusão do grupo em nossa sociedade;

c) a prática sociocultural em que será feita a ligação entre as partes anteriores, de forma a trazer à tona questões de ideologia, poder e hegemonia oriundas nas diferentes posições assumidas frente ao projeto Clarinha.

É importante frisar que, sob outro enfoque, os problemas advindos do processo de inclusão dos portadores de necessidades especiais têm sido uma preocupação de pesquisadores da área da Educação, como, por exemplo, Padoin (2002) e Souza e Freitas (2004), e da Psicologia como Tessaro (2005). Nosso trabalho, dentro dessa perspectiva, pode ser uma contribuição da Lingǘstica Aplicada que pode ter um impacto positivo no meio, ao refletir sobre o papel da linguagem nos processos de representação do portador de necessidades especiais na mídia.

Dessa forma, a principal razão para a utilização desse quadro teórico-metodológico, para além de sua própria agenda, é a visão da linguagem como texto - local em que se materializam discursos -, prática discursiva - por envolver o processo de produção, distribuição e consumo do texto - e prática social ao procurar ligar as dimensões anteriores em torno de conceitos como os de poder, ideologia e 
hegemonia, a partir de elementos sociais (cf. FAIRCLOUGH, 1989, 1995, 2001a, 2001b, 2005).

É relevante esclarecer também que existem diferenças importantes a serem consideradas com relação aos veículos em que foram publicados os textos que constituem nosso corpus - jornal e revista de informação geral.

O Jornal, segundo Dines (1986, p. 77), “o mais legítimo e duradouro veículo impresso depois do livro - condicionou o ser humano contemporâneo a um processo de saber". De acordo com o autor, o leitor de hoje não quer apenas saber o que acontece, pois almeja assegurar-se da sua situação dentro do que acontece, o que só ocorre se a informação possuir uma dimensão comparada, remeter ao passado, interligar-se com outros fatos, incorporar o fato a uma tendência e mostrar sua projeção para o futuro (p. 90).

Dessa forma, o jornal vai ajudando a construir realidades, a formar opiniões e pensamentos a partir de um processo de imaginação, uma vez que, conforme já visto, o discurso da mídia é, sobretudo e contrariamente ao que se pensa no senso comum, uma representação. $\mathrm{O}$ jornal, devido a sua periodicidade diária, constitui, então, para o autor, o melhor instrumento para a obtenção desse material utilitário que vai tornar a existência em sociedade, não apenas possível como mais fácil (cf. DINES, 1986, p. 97).

As revistas semanais, por sua vez, segundo explicitações de Vilas Boas (1996), foram criadas para preencher os vazios deixados pelas coberturas dos outros meios de comunicação, como jornais, rádio e televisão. Nas palavras do autor, "com mais tempo para extrapolações analíticas do fato, as revistas podem produzir textos mais criativos, utilizando recursos estilísticos geralmente incompatíveis com a velocidade do jornalismo diário, [por isso] a reportagem interpretativa é o forte" (p. 9).

Segundo Vilas Boas (1996), considerados os valores ideológicos, as revistas exigem textos elegantes e sedutores, mas 
estes não seguem regras muito rígidas, para que seja possível conciliar técnicas jornalísticas e literárias. Por outro lado, para ele, o estilo magazine ainda guardaria especificidades por praticar um jornalismo de maior profundidade, sendo mais interpretativo e documental que o jornal, o rádio e a TV. Dessa maneira, com a periodicidade semanal, torna-se possível fazer jornalismo daquilo que ainda está em evidência nos noticiários, o que é somado à pesquisa, à documentação e também à riqueza textual.

Conforme conclui o autor, "revista e jornal são, além de tudo, circunstancialmente diferentes", [sendo que] "a periodicidade é fator determinante do estilo de texto de uma revista" (p. 101). Como as revistas chegam às bancas da mesma forma que qualquer outro produto, "elas precisam de atrativos que as diferenciem do jornalismo dinâmico e veloz de todos os dias" (VILAS BOAS, 1996, p. 101).

\section{O "PROJETO CLARINHA" E A REPRESENTAÇÃO DO DOWN NA MÍDIA: ELEMENTOS LINGÜÍSTICO- DISCURSIVOS PARA ANÁLISE SOCIOCULTURAL}

\subsection{Focalizando os textos}

Conforme explicitado anteriormente, utilizaremos, nesta análise, Texto A para nos referir ao texto "Uma boneca com Down", publicado na revista "Época" e Texto B, para nos referir ao texto "Boneca de 'Páginas da vida' sofre rejeição", publicado na "Folha de São Paulo". E, inicialmente, do ponto de vista de construção textual, é importante frisar a existência de diferenças nas escolhas léxico-gramaticais e no conteúdo trazido pelos dois textos.

No texto A, temos a expressão "boneca com síndrome de Down", uma forma talvez de humanização do objeto, já que a mostra como portadora da Síndrome. E, do ponto de vista 
financeiro, é relevante destacar a frase "parte da renda com a venda do produto será doada à Associação de Voluntários do Hospital Infantil Darcy Vargas, em São Paulo", pois o partitivo "parte da" - dá margem a perguntar sobre para onde a(s) outra(s) parte(s) irá(ão), embora seja especificado que existe uma associação de voluntários que ficará com um montante do que for arrecadado. A existência de uma associação pode servir de elemento tranqüilizador dos leitores quanto à possibilidade de fraudes e corrupção, inclusive atenuando o possível questionamento exposto.

Do ponto de vista do conteúdo global dos textos, temos também um traço importante da forma como foram produzidos. $\mathrm{O}$ texto A pode ser considerado mais otimista que o $\mathrm{B}$, o que fica claro por já se ter um resultado frustrado do projeto sendo colocado em B e A ter sido publicado antes do lançamento da boneca.

A primeira frase do texto A - "Clarinha, personagem de Joana Mocarzel na novela Páginas da Vida, vai virar boneca." carrega em si um significado polissêmico, uma vez que, como a atriz é uma linda menina, cuja foto inclusive foi colocada ao lado direito do texto e à esquerda da imagem da boneca, temos a possibilidade de interpretar a palavra "boneca" no sentido estrito ou como "sinonímia" de bonita, o que ajuda na construção positiva da boneca como um projeto social e economicamente rentável.

O otimismo também pode ser percebido no fato de o texto A marcar apenas uma vez as dificuldades de tornar o projeto uma realidade como se verifica na frase "Ela [Andréa Barbi] e a dentista Audrey Bósio buscavam desde 2005 algum fabricante de brinquedos que topasse a empreitada". Ou seja, havia mais de dois anos ("desde 2005") que procuravam um fabricante ("algum fabricante") que aceitasse ("topasse") fabricar a boneca, fato que é colocado como uma "empreitada", item lexical que pode indicar 
urgência, mas que, pela articulação de linguagem, é um indicador de dificuldade, ou seja, da existência de obstáculos.

$\mathrm{Na}$ frase= "A Walbert, empresa de brinquedos de São Paulo, topou.", a empresa especificada pelo aposto ("empresa de brinquedos de São Paulo") ganha destaque como comportante e devido à elipse que retoma a idéia de empreitada. Em virtude disso, é possível ocorrer uma valorização do comportamento da empresa e se gerar uma publicidade positiva para ela.

De forma diferente de A, o texto B traz, logo no início, uma explicação exata que diferencia o ser humano do objeto: "boneca com característica de portador de síndrome de Down", inclusive buscando o termo politicamente correto. $\mathrm{O}$ texto também não traz uma associação para receber a renda obtida com a venda do produto ou mesmo parte dela, mas o hospital enquanto instituição é que será contemplado com a arrecadação - "A renda irá para o Hospital Infantil Darcy Vargas, de São Paulo".

Em outras palavras, no caso de B, tudo o que for arrecadado - e não parte - irá não para uma associação de voluntários, mas para o hospital. Há uma diferença na produção do texto, na distribuição por causa dos veículos (jornal e revista) e, como não temos o mesmo conteúdo informacional, pode-se afirmar que haverá diferença no consumo.

Em B temos "A boneca está sendo produzida por uma fábrica do interior de São Paulo, a Walbert", ou seja, nesse caso, temos a palavra "interior" que, pelo conteúdo assomado à progressão informacional do texto, pode indicar "pouco caso", pois grandes empresas não se interessaram por algo considerado socialmente nobre e importante como o projeto Clarinha. Por outra via, enquanto a Walbert ganhou destaque como comportante em A, valorizando a empresa por seu comportamento, em B, ela o perde ou, pelo menos, tem esse valor enfraquecido, quando passa a ter posição secundária numa expressão apositiva no final da frase. 
O que chama bastante a atenção em B é uma quantidade maior de marcação das dificuldades, como "o brinquedo até agora só foi vendido para três grandes empresas". Ou seja, o conteúdo da expressão "até agora só" ainda se fortalece quando se coloca "para três grandes empresas", pois indica a idéia de "rejeição", item lexical colocado logo no título do texto. Isso se justifica, já que empresas de maior porte não se interessaram pelo projeto e as de pequeno porte sequer foram mencionadas. Da mesma forma, quando se coloca que as idealizadoras do projeto "ouviram de uma rede de supermercados que o grupo está sem verba para investir no produto", temos, no processo comportamental "ouviram" em articulação na frase, um tom de desculpa num sentido que poderia ser tomado como negativo.

Em "uma famosa loja de brinquedos sequer tem atendido aos pedidos de reuniões com as mães", temos o qualificativo "famosa" em relação ao vocábulo adverbial "sequer" indicando irrelevância e/ou dificuldade, ou seja, o desinteresse pelo projeto e a palavra "pedido", marcando o insucesso das mães, pois acreditavam que tudo seria mais fácil.

Ao tomar a fala de Audrey Bósio em discurso direto, informado pelas aspas e pelo verbo elocutivo - processo verbal em lingüística sistêmico-funcional - "diz", percebemos nas partes "a gente pensou que seria mais fácil" e "apesar da divulgação, ninguém nos procurou até agora", a frustração por parte de quem possuía planos importantes para o projeto. Isso pode ser indicado pela posição de Audrey como dizente responsável pela informação e pelo conteúdo da verbiagem, revelando uma noção por parte do participante quanto à dimensão do projeto, conhecimento da realidade do portador da síndrome de Down e uma posição de otimismo mostrada na circunstância ("até agora"). Isso também pode ser percebido na atitude tomada por Audrey de desenvolver o projeto. 
É importante destacar a frase "Acho forte falar em preconceito", pela incerteza contida no processo mental "acho", que não descarta a possibilidade de existir preconceito, conforme se pode verificar no conteúdo global do pensamento. Isso se reforça pela primeira pessoa na posição de experienciador e "falar em preconceito" na posição de fenômeno, intensificado pela palavra "forte". Essa frase é seguida de "Isso é medo do diferente, tudo que é novo assusta". O dêitico "isso" - referente que retoma toda a situação exposta - indica a troca da palavra "preconceito" por "medo", associada à idéia da diferença, em termos de diversidade. E esse pensamento é fechado com a idéia de que novidade "assusta", processo comportamental que tem como alcance uma oração cujo conteúdo poderia ser colocado como atenuador da situação, o que pode ser verificado na característica ("medo do diferente").

A idéia de rejeição que, depois de colocada no título de B, permeia todo o texto é fortalecida por outra fala entre aspas, agora com outro processo que pode ser considerado por um lado mental e por outro fortalecido como comportamental - "avaliar": "Acredito que as lojas não sabem qual será a reação do consumidor e estão esperando para comprar". Nesse sentido, é interessante perceber que, pela construção do texto que reproduz em discurso direto a fala de Audrey Bósio, ela torna-se, ao mesmo tempo, experienciador e comportante: no primeiro caso, pelo aspecto mentalista exigido pelo próprio processo mental para se fazer uma avaliação e, no segundo, porque o processo "avaliar" também exige e fortalece um comportamento ativo da parte do participante.

Em outra análise, o processo inicial utilizado por Audrey é mental - "acredito" - e, pela articulação de idéias, reforça-se o otimismo por parte de quem quer que um projeto dê certo. Mais uma vez temos a primeira pessoa na posição de experienciador e como fenômeno algo otimista da parte de quem pretende ter uma experiência positiva. É interessante observar que, nas falas 
reproduzidas em discurso direto, tanto em A quanto em B, temos um número elevado de processos mentais ("queremos", "pensou", "acho", "acredito"), Audrey sempre na posição de experienciador e os fenômenos indicando uma positividade de experiência requerida por esse participante. Isso se justifica quando pensamos no valor dos processos e na posição dos participantes, ou seja, temos uma relação de percepção e apreciação calcadas nas crenças, planos e desejos do experienciador.

\subsection{Focalizando a prática discursiva: aspectos da relação produção, distribuição e consumo dos textos}

Conforme visto na seção anterior, a léxico-gramática e o conteúdo dos textos indicam diferenças que vão além das características dos gêneros ${ }^{1}$ e veículos que fazem a notícia do projeto Clarinha circular e, por isso, criam um objeto discursivo. $\mathrm{O}$ texto A possui um foco otimista e é praticamente desprovido de análise da situação que envolve um projeto dessa natureza, o que poderia ser feito se fossem satisfeitas as características requeridas pelo veículo, conforme Vilas Boas (1996). Ou seja, temos apenas uma notícia, pouco elaborada do ponto de vista da profundidade e análise que o tema requer e de que um veículo semanal dispõe. No texto B, temos um foco voltado para os empecilhos, o que, por ter sido publicado depois do lançamento da boneca, fica facilitado. Entretanto, o conteúdo não é apenas de uma notícia, pois, com ponto de vista bem definido, há certa profundidade, que o leva a cumprir melhor seu papel quando apontamos as características de uma revista, cujo único recurso utilizado foi o da imagem da boneca junto da foto de Joana Mocarzel, atriz que interpretou Clarinha em "Páginas da Vida", conforme uma frase explicativa.

\footnotetext{
${ }^{1}$ Para Fairclough (2001a, p. 161), gênero discursivo seria "um conjunto relativamente estável que é associado com, e parcialmente representa, um tipo de atividade socialmente aprovado, como a conversa informal, comprar produtos em uma loja, uma entrevista de emprego, um documentário de televisão, um poema ou um artigo científico." Logo, pode-se entender o gênero como uma ponte entre o discurso e a sociedade.
} 
Em outras palavras, tomando as características dos textos enquanto gêneros inseridos em revista de informação geral (Texto A) e jornal (Texto B), colocadas por Dines (1986) e de Vilas Boas (1996), podemos perceber uma espécie de contra-senso.

O jornal deveria trazer a notícia do "projeto Clarinha" com o objetivo maior de informar o leitor para que ele se assegurasse "da sua situação dentro do que acontece, o que só ocorre se a informação possuir uma dimensão comparada, remeter ao passado, interligar-se com outros fatos, incorporar o fato a uma tendência e mostrar sua projeção para o futuro" (DINES, 1986, p. 90). Nesse sentido, o gênero cumpre, a nosso ver, o seu papel, já que pode ser considerado possuidor de um conteúdo utilitário, informacional e dimensão comparada do fato, com relação ao aspecto sócio-histórico nele envolvido, indicando uma tendência que já era, pelo conteúdo e algumas pistas lingüístico-discursivas do texto A, esperada.

O texto da revista, por sua vez, segundo explicitações de Vilas Boas (1996), deveria preencher vazios deixados pelas coberturas dos outros meios de comunicação, como jornais, rádio e televisão. A despeito de o texto A ter sido publicado primeiro e não preencher todos esses quesitos, o autor também explicita que "com mais tempo para extrapolações analíticas do fato, as revistas podem produzir textos mais criativos, utilizando recursos estilísticos geralmente incompatíveis com a velocidade do jornalismo diário, [razão pela qual] a reportagem interpretativa é o forte" (p. 9). Nesse sentido, o conteúdo puramente noticioso, a linguagem simples e a falta de extrapolações ou, em outras palavras, análise e profundidade, mostram que não se caracteriza como um texto próprio para uma revista. Nesse sentido, o Texto B se encaixa melhor, e é nesse sentido que indicamos o contra-senso supracitado.

Segundo Vilas Boas (1996), o estilo magazine guardaria especificidades por praticar um jornalismo de maior profundidade, 
sendo mais interpretativo e documental que o jornal, o rádio e a TV. Dessa maneira, a periodicidade semanal tornaria possível fazer jornalismo daquilo que ainda está em evidência nos noticiários, o que é somado à pesquisa, à documentação e também à riqueza textual. Mais uma vez, a "riqueza", no sentido exposto, estaria ocorrendo no Texto B.

Se o texto das revistas de notícias deve, pelo tempo de publicação, utilizar recursos de que o jornal não dispõe por ser diário, pode-se considerar que, pelo conteúdo, os textos estão em veículos teoricamente inadequados como suportes para a publicação dos textos em análise, o que não quer dizer de forma generalizada que isso ocorra sempre.

Do ponto de vista dos discursos, podemos notar que pela positividade ou pela negatividade encontrada na representação do projeto, é possível notar diferenças discursivas interessantes que ajudam na construção discursiva da boneca. Destacam-se os seguintes discursos no Texto A: publicitário, promocional, econômico, de valorização do portador da síndrome de Down e de inclusão desse portador no universo social, especialmente no universo lúdico, já que seria representado por uma boneca com características de portador da síndrome. No Texto B, já se destaca um discurso de rejeição ao produto e, por isso, um discurso de exclusão que se instaura pelos inúmeros empecilhos vivenciados por quem possuía uma idéia socialmente nobre quanto a dar visibilidade a um grupo de cidadãos normalmente excluídos socialmente, por serem identificados por suas limitações originárias numa síndrome que não lhes retira, a priori, as capacidades. Nesse sentido, a análise textual, com base na léxico-gramática dos textos, comprova essa imbricação discursiva e pode indicar a reprodução de uma faceta preconceituosa de nossa sociedade, que tende a excluir o diferente em vez de respeitá-lo e se abrir para uma nova identidade para o grupo, que poderia ser visto pelo viés de suas capacidades. 


\subsection{Focalizando a prática social}

Retornando a determinados elementos já aventados, o que chama a atenção é que, do ponto de vista social, como a mídia é um local de difusão em massa de informações, essas, por sua vez, trazendo e envolvendo valores, crenças e ideologias, é possível notar que uma tentativa de dar visibilidade a um grupo marginalizado socialmente não obteve êxito, o que está ligado à hegemonia e poder existente numa idéia de "normalidade" que socioculturalmente o portador de Síndrome de Down não representa.

As articulações intratextuais, intra e interdiscursivas apontam para uma rejeição esperada pela posição que normalmente já é do grupo, ou seja, por uma identidade calcada em preconceito e ligada às limitações e não às capacidades dos portadores da síndrome.

Nesse sentido, pode-se afirmar que existem direitos de uma parcela da população sendo violentados por um preconceito sóciohistórico-cultural que precisa ser discutido em múltiplos espaços, revisto e, quiçá, derrubado. Essa é uma das formas de tentar transformar o modo como a sociedade vê os portadores de Down, procurando causar instabilidade e possivelmente modificar essa situação de vulnerabilidade em que eles se encontram.

A supremacia de uma maioria considerada normal calca-se num padrão de suposta normalidade, fruto de modelos perpetuados discursivamente na cultura, muitas vezes de forma subliminar e que pressionam a todos que possam ser considerados diferentes a adotá-los, criando uma ilusão de pertencimento e inclusão, ou, por outro lado, rejeição àqueles que não se adequarem a eles.

E, nesse sentido, por causa do mesmo fenômeno sociocultural, o que, de forma global, se percebe é um distanciamento cada vez maior de vários segmentos por questões políticas, econômicas, sociais, culturais, religiosas, étnicas, de gênero social, de saúde, dentre outras, devido à reprodução de estereótipos negativos, fundamentados em modelos excludentes e preconceituosos, que geram reclusão, conflito e rejeição. 


\section{ALGUMAS CONSIDERAÇÕES}

A análise dos textos indica que o grupo dos portadores da síndrome de Down continua silenciado, apesar de a personagem Clarinha, da novela "Páginas da Vida", ter trazido à tona a situação desconfortável por ela vivida sendo, muitas vezes, vítima de preconceito, sua pouca visibilidade e a possibilidade de transformação representada pelo projeto da boneca. Ou seja, mesmo quando, aparentemente, os portadores de Down são inseridos num espaço importante de difusão do pensamento e da informação como a mídia, não se verifica efetivamente nenhuma mudança.

A partir das pistas lingǘsticas encontradas na materialidade textual, algumas questões sociais e culturais importantes puderam ser levantadas e discutidas, como a importância do grupo por si, sua capacidade para além de suas limitações e a necessidade de que seja notado como um segmento real de uma sociedade caracterizada pela diversidade.

Deve-se destacar que culturalmente não somos preparados para a diversidade e que rejeição, medo e preconceito constituem uma das formas de lidar com a diferença a qual precisa ser mudada para uma posição em que o respeito tome esse lugar. Lutar por igualdade não parece ser uma estratégia benéfica, pois nenhum segmento da sociedade será, no sentido lato da palavra, igual ao outro, mas lutar por visibilidade na tentativa de que todos os segmentos sejam respeitados e respeitem-se uns aos outros em suas diferenças pode levar a uma sociedade mais justa, fraterna e, quiçá, verdadeiramente democrática.

A análise indica que o hibridismo discursivo e as diferentes opiniões relacionadas aos discursos apontam também para diferentes visões sobre o grupo que a boneca representa, havendo uma tensão entre o lado social, cujo objetivo é o de trazer a diversidade à baila e notoriedade para o grupo, refletindo sobre a necessidade de inclusão e visibilidade social, e o lado publicitário, que visa ao lucro, mas pode ter seu pleito "prejudicado", se o produto não tiver saída no mercado por representar um grupo que não seja o considerado "normal". Embora as idealizadoras do projeto mantenham-se otimistas, o texto A, 
modestamente, e principalmente o texto $\mathrm{B}$ mostram a dificuldade que poderiam enfrentar e, efetivamente, enfrentaram.

Como se pôde ver, os textos retratam os dois momentos na forma de otimismo e de rejeição. Quem idealizou o projeto mantém seu posicionamento, mas os conflitos discursivos indicam tensões e, para além dessas, uma forma naturalizada e estereotipadamente negativa de ver o portador da síndrome de Down, como um segmento à parte, pouco visível ou visível por suas limitações. E, por estar à margem, este passa a não ser condizente para ser incorporado no universo lúdico caso específico do projeto da boneca - ou assumir um lugar que the pertence por direito, enquanto cidadão.

Tudo isso indica que precisamos, urgentemente, de uma transformação de pensamento que se projete em mudança de atitude. Precisamos de uma cultura que se dissemine na sociedade na forma de respeito às diferenças que lhe são inerentes. No caso específico em análise, é importante que o portador de Down passe a ser visto por suas capacidades e não rotulado, representado, identificado e conhecido por suas limitações.

\section{REFERÊNCIAS}

ADORNO, S. A violência na sociedade brasileira: um painel inconcluso em uma democracia não consolidada. Sociedade \& Estado, São Paulo, v. 1, n. 2, p. 299-342, Jul./Dez. 1995.

CAETANO, P. H. A palavra-chave racismo e suas relações lexicais: uma análise crítica das relações raciais brasileiras em corpus de jornal impresso. 2007. Tese (Doutorado) - FALE/UFMG, Belo Horizonte.

CALDAS-COULTHARD, C. R. From discourse analysis to critical discourse analysis: the differential re-presentation of women and men speaking in written news. In: SINCLAIR, J.; HOEY, M.; FOX, G. (Eds.). Techniques of description: spoken and written discourse. London: Routledge, 1993. p. 196208.

Women who pay for sex. And enjoy it: transgression versus morality in women's magazines. In: CALDAS-COULTHARD, C. R.; COULTHARD, M. 
(Eds.). Texts and practices: readings in critical discourse analysis. London: Routledge, 1996. p. 250-270.

CARMO, C. M. Relações lexicais, interdiscursividade e representação: o sincretismo e a questão racial em corpus de jornais e revistas brasileiras. 2005. Tese (Doutorado) - FALE/UFMG, Belo Horizonte.

CASTRO, D. Boneca de 'Páginas da Vida' sofre rejeição. Folha de São Paulo, São Paulo, Ilustrada, 13 março, p. E4, 2007.

COSTA, I. M. S. Auto-imagem e papel social do portador de Síndrome de Down. Tuiuti, Curitiba, v. 6, n. 2, p. 61-72, set. 1996.

DINES. A. O papel do jornal. São Paulo: Summus Editorial, 1986.

EGGINS, S. An introduction to systemic functional linguistics. London: Pinter, 1994.

FAIRCLOUGH, N. Language and power. London: Longman, 1989.

. Media discourse. London: Longman, 1995.

Discurso e mudança social. Tradução de Izabel Magalhães. Brasília: Ed. da UnB, 2001a.

A análise crítica do discurso e a mercantilização do discurso público: as universidades. In: MAGALHÃES, C. M. (Org.). Reflexões sobre a análise crítica do discurso. Belo Horizonte: UFMG, 2001b. p. 31-82.

. Critical discourse analysis in transdisciplinary research. In: WODAK, R.; CHILTON, P. (Eds.). A new agenda in (Critical) Discourse Analysis: theory, methodology and interdisciplinarity. Amsterdam; Philadelphia: John Benjamins Publishing Company, 2005. p. 53-70.

FARR, R. M. Representações sociais: a teoria e sua história. In: GUARESCHI, P.; JOVCHELOVITH, S. (Orgs.). Textos em representações sociais. Petrópolis: Vozes, 2003. p. 31-59.

FAUSTO NETO, A. Comunicação e mídia impressa: estudo sobre AIDS. São Paulo: Hackers Editores, 1999.

FOWLER, R. Language in the news: discourse and ideology in the press. London; New York: Routledge, 1991.

GARRET, P.; BELL, A. (Eds.). Approaches to media discourse. Oxford: Blackwell Publishers Ltd., 1998. 
HALLIDAY, M. A. K. An introduction to functional grammar. London: Edward Arnold, 1985a.

Dimensions of discourse analysis: grammar. In: VAN DIJK, T. A. (Ed.). Handbook of discourse analysis: dimensions of discourse. V. 2. London: Academic Press, 1985b. p. 29-56.

; MATTHIESSEN, C. M. I. M. An introduction to functional grammar. 3rd ed. Great Britain: Arnold, 2004.

HEBERLE, V. M. An investigation of textual and contextual parameters in editorial of women's magazines. 1997. Tese (Doutorado) - UFSC, Florianópolis.

- Análise crítica do discurso e estudos de gênero (gender): subsídios para a leitura e interpretação de textos. In: FORTKAMP, M. B. M.; TOMITCH, L. M. B. (Orgs.) Aspectos da lingüística aplicada: estudos em homenagem ao professor Hilário Inácio Bohn. Florianópolis: Insular, 2000. p. 289-316.

JOVCHELOVITCH, S. Vivendo a vida com os outros: intersubjetividade, espaço público e representações sociais. In: GUARESCHI, P.;

JOVCHELOVITH, S. (Orgs.). Textos em representações sociais. Petrópolis: Vozes, 2003. p. 63-85.

LOCKE, T. Critical discourse analysis. London; New York: Continuum, 2004. (Continuum Research Methods Series)

MACHADO, F. Uma boneca com Down. Época, São Paulo, n. 459, 5 março, p. 24, 2007.

MAGALHÃES, C. M. Interdiscursividade e conflito entre discursos sobre raça em reportagens brasileiras. Linguagem em (Dis)curso, v. 4, n. esp., p. 35-60, 2004.

MARTIN, J. R. Cohesion and texture. In: SHIFFRIN, D., TANNEN, D.; HAMILTON, H. E. (Eds.). The handbook of discourse analysis. Oxford, UK; Malden, US: Blackwell Publishers, 2001. p. 35-53.

MATTHIESSEN, C.; HALLIDAY, M.A.K. Systemic functional grammar: a first step into the theory. 1997. Disponível em:

$<$ http://lael.pucsp.br/ tony/cursos/sfl/SFG_Halliday_Matth.htm>.

MAZZOTTI, A. J. A. A abordagem estrutural das representações sociais.

Psicologia da Educação, São Paulo: PUC-SP, ns. 14-15, p. 17-37, 2002.

CARMO - Representação do Down... 
MOSCOVICI, S.; NEMETH, C. Minority influence. In: NEMETH, C. (Org.). Social psychology: classic and contemporary integrations. Chicago: Rand McNally, 1974. p. 217-250.

O'REGAN, F. Sobrevivendo e vivendo com necessidades educacionais especiais. Porto Alegre: Artmed, 2007.

PADOIN, B. L. Inclusão do portador de necessidades educativas especiais. Virtus, Tubarão, v. 2, n. 1, p. 345-357, Jul. 2002.

PINTO, M. J. Comunicação e discurso: introdução à análise de discursos. São Paulo: Hackers Editores, 1999.

PVESCHEL, S. M. (Org.). Síndrome de Down: guia para pais e educadores. Campinas: Papirus, 1993.

RODRIGUES, A. D. O campo dos media. Lisboa: Vega, [s.d.].

Estratégias de comunicação. Lisboa: Editora Presença, 1988.

SCOLLON, R. Mediated discourse as social interaction: a study of news discourse. London; New York: Longman, 1998.

SÉGUIN, E. Minorias e grupos vulneráveis: uma abordagem jurídica. Rio de Janeiro: Forense, 2002.

SOUZA, M. L. L; FREITAS, S. N. O portador de necessidades especiais e sua escolarização. Perspectiva, Erechim, RS, v. 28, n. 102, p. 91-99, Jun. 2004.

TESSARO, N. S. Inclusão escolar: concepções de professores e alunos da educação regular e especial. São Paulo: Casa do Psicólogo, 2005.

VILAS BOAS, S. O estilo magazine: o texto em revista. São Paulo: Summus Editorial, 1996.

WERNECK, C. Muito prazer, eu existo: um livro sobre o portador da síndrome de Down. São Paulo: Memnon, 1992.

WODAK, R. Do que trata a ACD - um resumo de sua história, conceitos importantes e seus desenvolvimentos. Linguagem em (Dis)curso, v. 4, n. esp., p. 223-243. 2004.

ZALUAR, A. M. Violence in Rio de Janeiro: styles of leisure, drug use, and trafficking. International Social Science Journal, Londres and Paris, UNESCO, v. LIII, n. 3, p. 369-379, 2001.

Exclusion and public policies: theoretical dilemmas and political alternatives. Revista Brasileira de Ciências Sociais, v. 1, p. 25-42, 2000. 
. Desafios para o ensino básico na visão dos vulneráveis. Sociologias,

Porto Alegre, v. 1, p. 228-249, 1999.

Gangues, galeras e quadrilhas: globalização, juventude e violência. In:

VIANNA, H. (Org.). Galeras cariocas: territórios de conflitos e encontros culturais. Rio de Janeiro: Editora UFRJ, 1997. p. 17-57.

\section{ANEXO}

\section{Texto A: Uma boneca com Down}

Clarinha, personagem de Joana Mocarzel na novela Páginas da Vida, vai virar boneca. É a primeira vez que uma boneca com síndrome de Down será produzida em escala industrial no Brasil. O lançamento deve ocorrer a partir desta semana. A idéia partiu de duas amigas, mães de crianças portadoras de Down. "Queremos que as crianças se identifiquem nas bonecas", diz a estilista Andréia Barbi. Ela e a dentista Audrey Bósio buscavam desde 2005 algum fabricante de brinquedos que topasse a empreitada. A Walbert, empresa de brinquedos de São Paulo, topou. Parte da renda com a venda do produto será doada à Associação de Voluntários do Hospital Infantil Darcy Vargas, em São Paulo.

Flávio Machado. (Revista Época)

\section{Texto B: Boneca de "Páginas da Vida" sofre rejeição}

A boneca Clarinha, inspirada na personagem de "Páginas da Vida" interpretada por Joana Mocarzel, está sofrendo resistência de lojas de brinquedos. Clarinha é a primeira boneca com características de portador de síndrome de Down.

O brinquedo até agora só foi vendido para três grandes empresas. As Lojas Americanas adquiriram 2.500 unidades e os Armarinhos Fernando, comércio popular da rua 25 de Março (centro de São Paulo), outras 120. O terceiro comprador foi uma loja do Rio de Janeiro.

Os idealizadores da boneca, mães de crianças com Down, ouviram de uma rede de supermercados que o grupo está sem verba para investir no produto. Uma famosa loja de brinquedos sequer tem atendido aos pedidos de reuniões com as mães.

"Por ser uma boneca de uma personagem de novela, a gente pensou que fosse mais fácil vender, mas estamos tendo dificuldades. Apesar da divulgação, 
ninguém nos procurou até agora. Acho forte falar em preconceito. Isso é medo do diferente, tudo o que é novo assusta", diz Audrey Bosio, 30, líder do projeto que criou Clarinha,

"Acredito que as lojas não sabem qual será a reação do consumidor e estão esperando para comprar”, avalia Audrey.

A boneca está sendo produzida por uma fábrica do interior de São Paulo, a Walbert. A Globo cedeu os direitos. A renda irá para o Hospital Infantil Darcy Vargas, de São Paulo.

Daniel Castro. (Jornal Folha de São Paulo)

Recebido em 17/09/07. Aprovado em 20/12/07.

Title: Down representation and conflicts with the different: discursive aspects of the Clarinha project, a doll with traces of Down Syndrome

Author: Cláudio Márcio do Carmo

Abstract: This article is part of a broader project entitled "Inclusion, representation and identity construction of minorities and vulnerable groups in the media", which uses the theoretical and methodological framework of Critical Discourse Analysis proposed by Norman Fairclough. The focus of this project is on the silencing of these groups, even when they seem to be inserted in the media, and on the discursive conflicts that emerge from this attempt of inclusion. The corpus of this study is composed of two texts: one published in "Época" magazine, before the release of "Clarinha" - a doll with traces of Down syndrome; and the other published in the newspaper "Folha de São Paulo" after the doll's release. The analysis indicates the presence of discursive hybridism, indicating different views of the group that the doll represents, pointing out to a tension between the social sphere and advertising goals. This conflict indicates a general inability to deal with diversity.

Keywords: media; representation; Down Syndrome; discourse.

Titre: Représentation du Down et des conflits avec le dissemblable: aspects discursifs du projet "Petite Claire", une poupée avec des traits du Syndrome de Down

Auteur: Cláudio Márcio do Carmo

Résumé: Cet article est présenté comme composant majeur, nommé "Insertion, représentation et construction identitaire de minorités vulnérables dans les médias", qui s'en sert du tableau théorico-méthodologique de l'Analyse du Discours de Norman Fairclough. L'intérêt tombe sur le moyen dont ces groupes s'étant tu, même quand, apparemment, sont insérés dans les médias, et sur les conflits et affrontements discursifs venus de cet essai d'inclusion. Dans ce travail, on analyse deux textes, l'un publié dans l'hebdomadaire «Época », avant la sortie de «Petite Claire », poupée ayant les traits du Syndrome de Down, et d'un autre publié par "Folha de São Paulo », après son lancement. L'analyse désigne l'hybridisme discursif, signalant des visions 
différentes sur le groupe représenté par la poupée, ayant une tension entre le côté social et l'objectif publicitaire. S'infiltant dans cette déviation, on se rend compte d'une inaptitude générale pour travailler avec la diversité.

Mots-clés: médias; représentation; Syndrome de Down; discours.

Título: Representación de Down y conflictos con lo diferente: aspectos discursivos del proyecto "Clarinha", una muñeca con rasgos del Síndrome de Down

Autor: Cláudio Márcio do Carmo

Resumen: El presente artículo se presenta como parte de un proyecto mayor, intitulado "Inserción, representación y construcción de identidad de minorías y grupos vulnerables en los medios", que utiliza el cuadro teórico-metodológico del Análisis Crítico del Discurso de Norman Fairclough. El interés recae sobre el modo como esos grupos son silenciados, inclusive cuando, aparentemente, son inseridos en los medios, y sobre los conflictos y embates discursivos provenientes de ese intento de inclusión. En este trabajo, son analizados dos textos, uno publicado en la revista "Época", antes del lanzamiento de Clarinha, muñeca con rasgos del Síndrome de Down, y otro publicado en la "Folha de São Paulo", después de su lanzamiento. El análisis indica el hibridismo discursivo, apuntando diferentes visiones sobre el grupo que la muñeca representa, habiendo una tensión entre el lado social y el objetivo publicitario. Pasando por alto este detalle, se percibe una falta de preparo general para lidiar con la diversidad.

Palabras-clave: medios; representación; Síndrome de Down; discurso. 